\title{
Exposure to Pesticides and Health Effects on Farm Owners and Workers From Conventional and Organic Agricultural Farms in Costa Rica: Protocol for a Cross-Sectional Study
}

Samuel Fuhrimann ${ }^{1}$, PhD; Mirko S Winkler ${ }^{2,3}$, PhD; Philipp Staudacher ${ }^{4,5}$, MSc; Frederik T Weiss ${ }^{4,5}$, MSc; Christian Stamm $^{4,5}, \mathrm{PhD}$; Rik IL Eggen ${ }^{4,5}, \mathrm{PhD}$; Christian H Lindh ${ }^{6}, \mathrm{PhD}$; José A Menezes-Filho ${ }^{7}, \mathrm{PhD}$; Joseph M Baker ${ }^{8}, \mathrm{PhD}$; Fernando Ramírez-Muñoz ${ }^{9}, \mathrm{PhD}$; Randall Gutiérrez-Vargas ${ }^{10}, \mathrm{PhD}$; Ana M Mora ${ }^{9}, \mathrm{PhD}$

\footnotetext{
${ }^{1}$ School of Public Health and Family Medicine, Faculty of Health Sciences, University of Cape Town, Cape Town, South Africa

${ }^{2}$ Swiss Tropical and Public Health Institute, Basel, Switzerland

${ }^{3}$ University of Basel, Basel, Switzerland

${ }^{4}$ Swiss Federal Institute of Aquatic Science and Technology (Eawag), Dübendorf, Switzerland

${ }^{5}$ Institute of Biogeochemistry and Pollutant Dynamics, Department of Environmental Systems Science, ETH Zürich, Zürich, Switzerland

${ }^{6}$ Division of Occupational and Environmental Medicine, Institute of Laboratory Medicine, Lund University, Lund, Sweden

${ }^{7}$ Laboratory of Toxicology, Faculty of Pharmacy, Federal University of Bahia, Bahia, Brazil

${ }^{8}$ Department of Psychiatry and Behavioral Sciences, School of Medicine, Stanford University, Stanford, CA, United States

${ }^{9}$ Central American Institute for Studies on Toxic Substances, Universidad Nacional, Heredia, Costa Rica

${ }^{10}$ Centro de Investigación y Diagnóstico en Salud y Deporte, Universidad Nacional, Heredia, Costa Rica
}

\section{Corresponding Author:}

Ana M Mora, $\mathrm{PhD}$

Central American Institute for Studies on Toxic Substances

Universidad Nacional

PO Box 86

Heredia, 3000

Costa Rica

Phone: 50622773677

Email: ana.mora.mora@una.cr

\begin{abstract}
Background: Pesticide use is increasing in low- and middle-income countries (LMICs) including Costa Rica. This increase poses health risks to farm owners, farm workers, and communities living near agricultural farms.

Objective: We aimed to examine the health effects associated with occupational pesticide exposure in farm owners and workers from conventional and organic smallholder farms in Costa Rica.

Methods: We conducted a cross-sectional study involving 300 owners and workers from organic and conventional horticultural smallholder farms in Zarcero County, Costa Rica. During the baseline study visit, we administered a structured, tablet-based questionnaire to collect data on sociodemographic characteristics, pesticide exposure, and health conditions (eg, respiratory and allergic outcomes and acute pesticide intoxication symptoms) and administered a neurobehavioral test battery (eg, Finger Tapping Test and Purdue Pegboard); we measured blood pressure, anthropometry (height, weight, and waist circumference), and erythrocytic acetylcholinesterase activity and also collected urine samples. In addition, a functional neuroimaging assessment using near-infrared spectroscopy was conducted with a subset of 50 study participants. During the follow-up study visit ( 2-4 weeks after the baseline), we administered participants a short questionnaire on recent pesticide exposure and farming practices and collected hair, toenail, and urine samples. Urine samples will be analyzed for various pesticide metabolites, whereas toenails and hair will be analyzed for manganese (Mn), a biomarker of exposure to Mn-containing fungicides. Self-reported pesticide exposure data will be used to develop exposure intensity scores using an exposure algorithm. Furthermore, exposure-outcome associations will be examined using linear and logistic mixed-effects regression models.
\end{abstract}

Results: Fieldwork for our study was conducted between May 2016 and August 2016. In total, 113 farm owners and 187 workers from 9 organic and 83 conventional horticultural smallholder farms were enrolled. Data analyses are ongoing and expected to be published between 2019 and 2020 . 
Conclusions: This study is one of the first to examine differences in health effects due to pesticide exposure between farm owners and workers from organic and conventional smallholder farms in an LMIC. We expect that this study will provide critical data on farming practices, exposure pathways, and how occupational exposure to pesticides may affect farm owners and workers' health. Finally, we hope that this study will allow us to identify strategies to reduce pesticide exposure in farm owners and workers and will potentially lay the groundwork for a future longitudinal study of health outcomes in farm owners and workers exposed to pesticides.

International Registered Report Identifier (IRRID)： DERR1-10.2196/10914

(JMIR Res Protoc 2019;8(1):e10914) doi: 10.2196/10914

\section{KEYWORDS}

acetylcholinesterase; agriculture; Costa Rica; farm workers; near-infrared spectroscopy; neurobehavioral outcomes; pesticides; pesticide exposure assessment; respiratory outcomes

\section{Introduction}

Pesticides are extensively used in agriculture and for control of vector-borne diseases across the globe [1,2]. Current data from the Food and Agriculture Organization suggest that pesticide use is increasing globally, with its largest growth in low- and middle-income countries (LMICs) in tropical contexts [3]. Notably, registered pesticides are often not assessed in tropical contexts, where decay rates of active ingredients and metabolites of pesticides differ from other settings [4] and regulatory bodies often fail to phase-out harmful pesticides or monitor their safe use [5]. In LMICs, the smallholder farming sector frequently struggles to use pesticides safely due to a lack of awareness and low risk perception among farm owners and workers [6-8].

Pesticide applicators (either farm owners or workers) in smallholder farms are often exposed to these chemicals at different stages of the process (eg, storage, mixing, preparation, and application) $[9,10]$. Therefore, uncontrolled and uninformed pesticide use can directly expose workers and surrounding communities through drift and pesticide residues in food and drinking water [11]. Several studies from LMICs have shown that acute pesticide poisoning represents an important cause of morbidity and mortality among farm workers [12]. In addition, long-term exposure to pesticides such as organophosphates and carbamates has been linked to a broad range of chronic health effects, including impaired neurobehavioral function (eg, cognitive and behavioral disorders), respiratory problems, obesity, and diabetes [13-17].

The characterization of pesticide exposures in LMICs is challenging due to the short half-lives of most of these chemicals in the human body, limited availability of biomarkers of exposure, and lack of epidemiological data [18-20]. As highlighted by a recent descriptive review [19], most studies in LMICs have relied on self-reported pesticide exposures. A few studies have generated pesticide exposure matrices, estimating exposure intensity indices using the amount of pesticide used and personal protective equipment worn during the applications $[18,21,22]$. However, these exposure matrices are prone to information bias and often lack validation against biomarkers of exposure in humans (eg, urine and blood) [18,19].

Several studies have examined the health effects of occupational pesticide exposure in tropical settings [23-29]. In addition, multiple studies outside of LMICs have assessed differences in pesticide use practices from conventional farming systems (ie, using synthetic pesticides) and organic (ie, using biological pest control; certified as organic by third-party agencies) farms [30]. Nevertheless, to the best of our knowledge, only one published study from Portugal has compared pesticide exposure and health outcomes in farm workers from both types of farms [31]. In the present study, we aimed to determine whether occupational pesticide exposure (assessed through self-reported data and biomarkers of exposure) affects the health of farm owners and workers from conventional and organic smallholder farms in Costa Rica.

\section{Methods}

\section{Objectives and Study Design}

We conducted a cross-sectional study of 300 farm owners and workers with repeated exposure assessment at two time points (to study the variability of pesticide exposure over time) between May 2016 and August 2016 (rainy season, during which the highest pesticide application is expected). The specific objectives of the project are as follows (Figure 1):

1. To assess occupational pesticide exposure in owners and workers of conventional and organic farms, using self-reported pesticide use data and biomarkers of pesticide exposure.

2. To evaluate the association of occupational pesticide exposure (determined using a pesticide exposure matrix and also biomarkers of exposure) with self-reported symptoms of acute intoxication in the last 12 months.

3. To examine the association of occupational pesticide exposure with self-reported respiratory and allergic outcomes in the last 12 months.

4. To evaluate the association between occupational pesticide exposure and cardiometabolic effects, such as adiposity and high blood pressure.

5. To assess the association of occupational exposure to organophosphates and carbamates with erythrocytic acetylcholinesterase (AChE) activity.

6. To assess the association of occupational pesticide exposure with neurobehavioral outcomes, such as working memory, visual perception, and fine motor function.

7. To examine the association of occupational pesticide exposure with changes in brain activity, assessed using functional near-infrared spectroscopy (fNIRS). 
This study is part of the Pesticide Use in Tropical Settings (PESTROP) Project, which aims to deepen our understanding of the environmental, health, and regulatory dimensions of pesticide use in conventional and organic agriculture in LMICs. The design of our research was partly informed by a study conducted in the same study area between 2014 and 2016 [32]. This study focused on the diagnosis of pesticide use in farms with conventional practices and highlighted unintended uses of pesticides among farm owners in Zarcero (eg, use of pesticides without appropriate training and personal protective equipment protection and discharge of pesticide containers into the environment). The findings of this study provided orientation on exposure pathways to be expected and influenced the definition of our study groups.

All study materials and procedures were approved by the human subjects committee of the Universidad Nacional in Costa Rica (UNA-CECUNA-ACUE-04-2016) and Ethical Board of the
Ethikkommission Nordwest- und Zentralschweiz in Switzerland (EKNZ-UBE 2016-00771). Written informed consent was obtained from all study participants at enrollment. Study results will be communicated back to participants and stakeholders at restitution workshops (Figure 2).

\section{Study Area}

The study was conducted in the Tapezco river catchment in the Zarcero County, Costa Rica (Figure 3). This river catchment features approximately 760 small-scale smallholder farms with conventional and organic farming practices $\left(\sim 4 \mathrm{~km}^{2}\right.$ of horticultural farms) [33] and has been previously used to monitor pesticide levels in the surface water near smallholder farms. Common crops in the area include potatoes, tomatoes, cabbage, carrots, lettuce, cilantro, and onions [32]; chlorothalonil, mancozeb, propineb, and phorate account for $>50 \%$ of the pesticides used in the County. Notably, potatoes and onions are the crops with the highest pesticide use per hectare [32].

Figure 1. Aims (bold text), research design details and tools used (tick) in the study conducted in Zarcero County, Costa Rica, 2016.

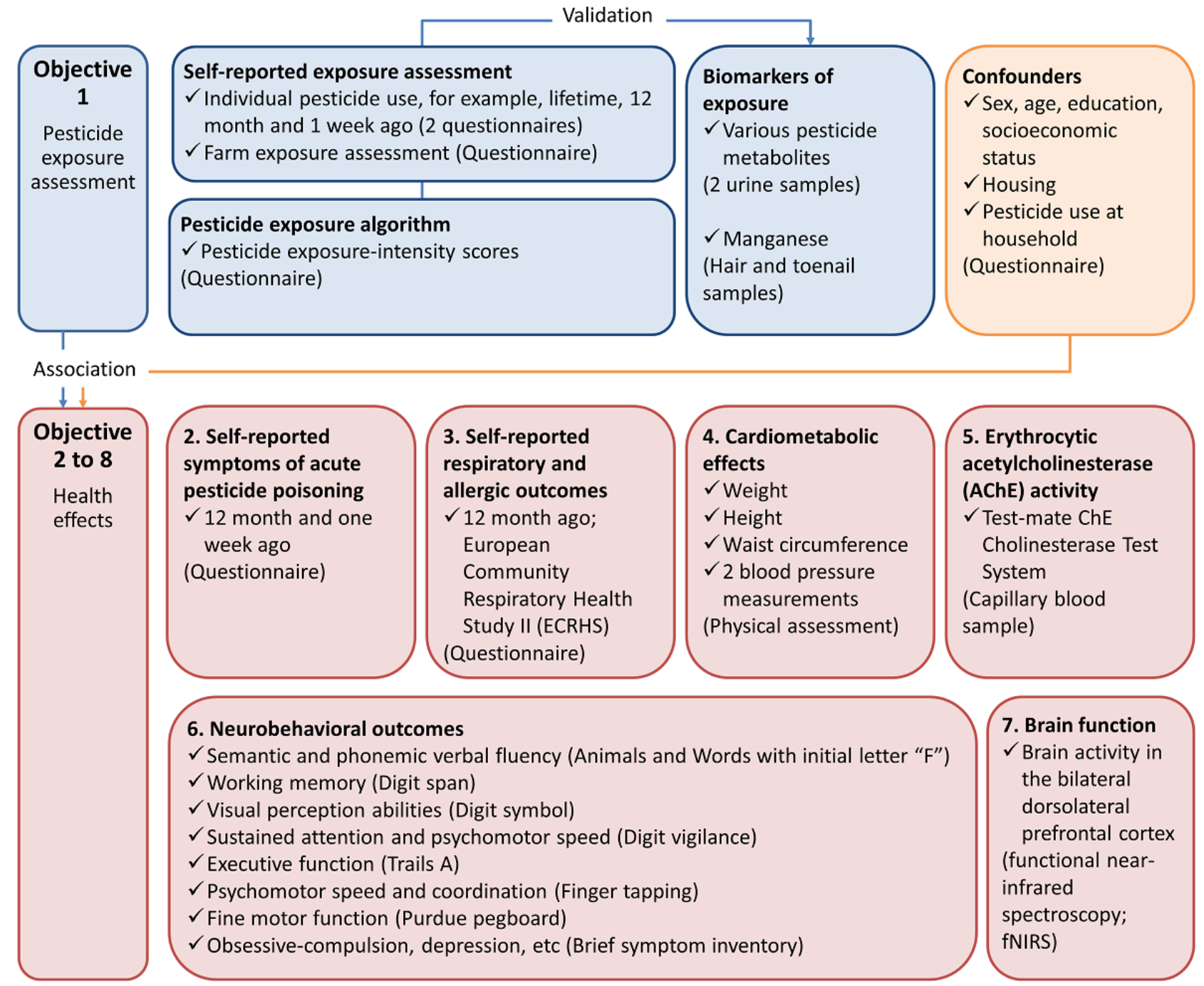


Figure 2. Diagram of the fieldwork setup in the Zarcero study, Costa Rica, 2016.

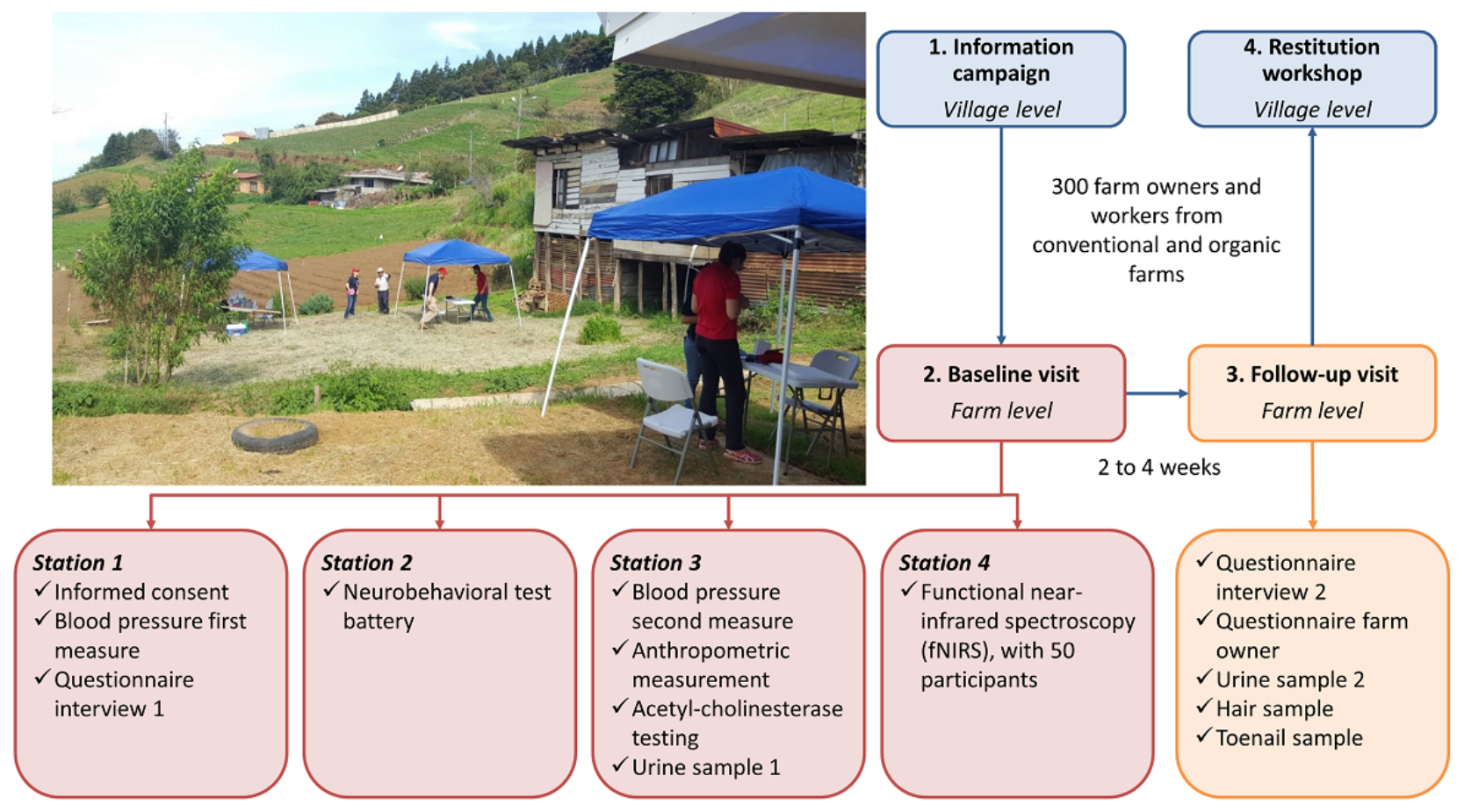

Figure 3. Study area (Tapezco river catchment) with global positioning system locations of 92 farms that were included in our study conducted in Zarcero County, Costa Rica, 2016. Shape files provided by Moraga (2015).

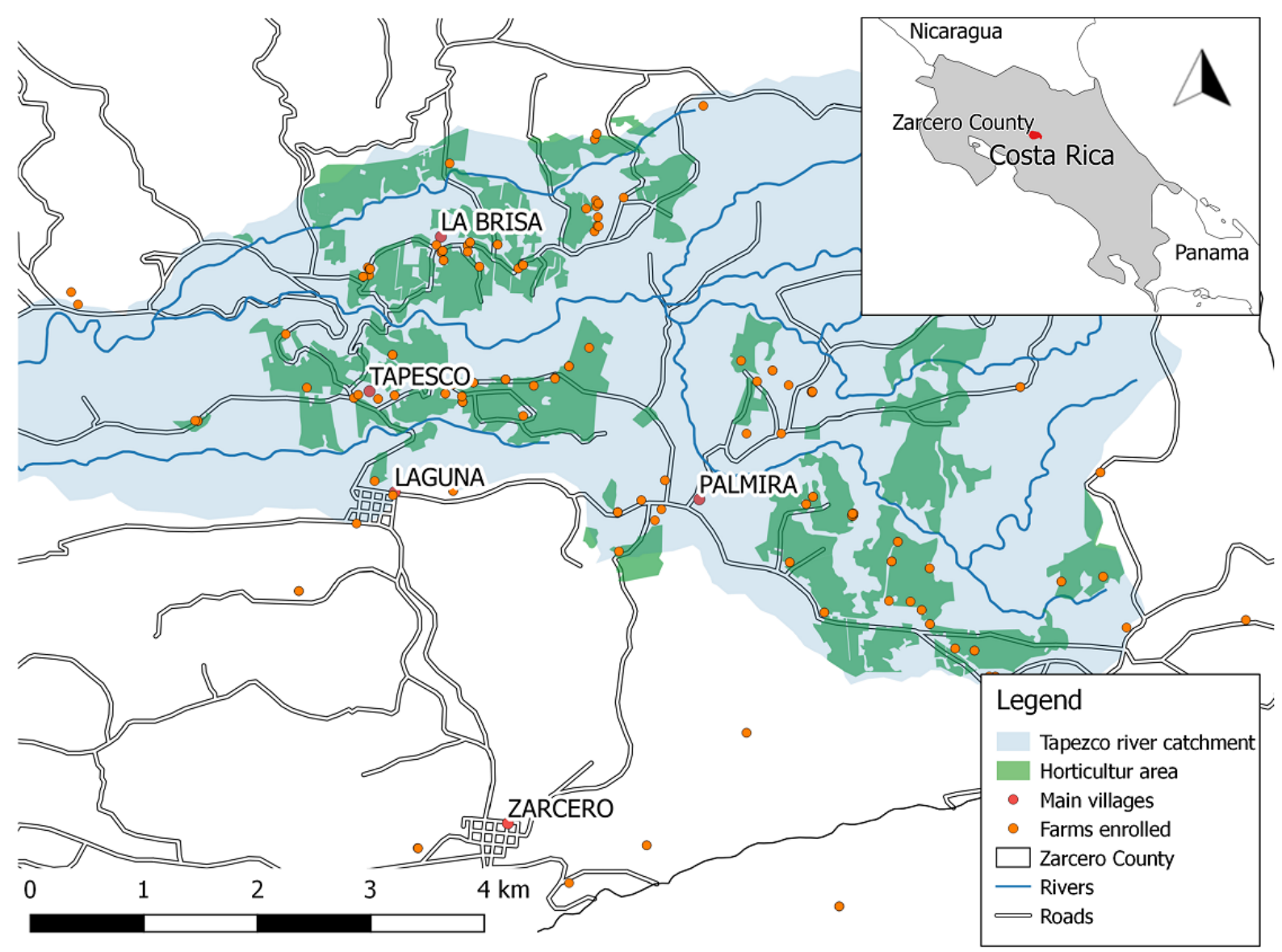




\section{Study Participants' Selection and Study Visits}

Conventional farms in the study area were identified using random global positioning system (GPS) points generated on the basis of smallholder land use data from 2015 (Moraga G, unpublished data, 2000) [34]. After a total of 200 GPS points were generated, study staff visited these locations and determined which ones corresponded to smallholder farms by contacting the farm owners or administrators. When the GPS point did not correspond to a horticultural farm, the closest smallholder farm within a radius of $1 \mathrm{~km}$ was registered; if no farm was nearby, the GPS point was dropped. Organic farms within the Tapezco river catchment or within $5 \mathrm{~km}$ from this area were identified using an existing list provided by the organic farmers' association or through onsite identification.

After organic and conventional farms in the study area were identified, farm owners were briefly informed about the study aims and procedures (initial visits to the farms are, henceforth, called Information campaign; Figure 3). If they showed interest in participating in the study, basic contact information was collected to schedule a later visit to their farms to enroll study participants. Eligible participants were farm owners, permanent workers, or temporary pesticide applicators, all aged $\geq 18$ years, who owned or worked in conventional farms located in the Tapezco river catchment or organic farms within or near the catchment area, and who did not have a diagnosis of psychiatric disease or used psychopharmacological medications.

Participants were visited twice during the study duration, either at the farms where they worked or at their homes (Figure 3). The baseline or initial study visits were conducted by two teams of 3 trained research assistants each and comprised 4 "Stations " (duration $~ 45$ minutes each) as follows: "Station 1" included the administration of the informed consent and a structured questionnaire to collect data on sociodemographic characteristics, occupational history, pesticide exposure at work and at home, medical history including respiratory and allergic outcomes in the last 12 months, and a blood pressure measurement; "Station 2 " included the administration of a neurobehavioral test battery (eg, Purdue Pegboard and Finger Tapping Test) and a checklist of acute pesticide intoxication symptoms in the last 12 months; "Station 3 " included measurements of the erythrocytic AChE activity, anthropometry (ie, height, weight, and waist circumference), and blood pressure (second measurement) and urine sample collection; and "Station 4 " included the fNIRS assessment (only completed by a subset of study participants).

The follow-up study visits (duration $\sim 15$ minutes, 2-4 weeks after the first visit) were conducted by two trained research assistants and included the administration of a short questionnaire on recent pesticide exposure (administered to all participants) and farming practices (administered only to farm owners) and collection of toenail and hair samples and a second urine specimen.

All study instruments were pilot-tested in 10 farmers. Study protocols were administered by trained research assistants in Spanish, and data were entered directly into tablets (Samsung Galaxy Note 10.1 N8010) via an entry mask using Open Data Kit [35]. Questionnaires and other study instruments are available per request.

\section{Power and Sample Size Calculation}

We based our sample size calculation on the difference in the erythrocytic AChE activity between organic and conventional farm owners and workers [36]. With a sample size of 300 farm owners and workers, the minimum number of farms to show a significant effect between the 2 groups was calculated to be 50 (ie, 25 conventional and 25 organic farms). In brief, we assumed an average cluster size of 6 farmers per individual farm (this assumption was derived from a pilot visit and expert opinion of local agronomists), an intraclass correlation coefficient (ICC) of 0.1 , a ratio of SDs of 1.5 between exposed and unexposed persons regarding the erythrocytic AChE activity, a significance level of $5 \%, 80 \%$ power, and an effect size of 0.4 , that is, a difference in the mean of the erythrocytic AChE activity between exposed and unexposed farm owners and workers of $0.4 \times \sqrt{ }[(1+2.25) / 2 \mathrm{SDs}]$.

\section{Interviews and Self-Report Pesticide Exposure}

Information on sociodemographic variables and occupational exposure to pesticides was collected using structured questionnaires (Table 1). During the baseline visit, study participants were asked about the crops that they had recently worked on and if they had prepared or applied pesticides. If they reported preparing or applying one of the 15 pesticides most commonly used in the study area (according to a previous study on good farming practices that was conducted in conventional farms from the study area, Table 2; [32]), detailed data on the mode of application, period, dose, frequency of pesticide applications, and personal protective equipment use were collected. In addition, participants were asked about their recent pesticide applications (prior to the collection of each urine sample), previous work in conventional or organic farms, and years of exposure to pesticides during their work life. During the follow-up visit, study participants were asked about changes in their work status and pesticide use since their baseline visit. In addition to the data described above, we collected information on farms' characteristics (eg, size, type of crops grown on the farm, farming practices including pest control management, and water sources located nearby) using a structured questionnaire that was administered only to farm owners. 
Table 1. Information collected during the baseline study visit using structured questionnaires.

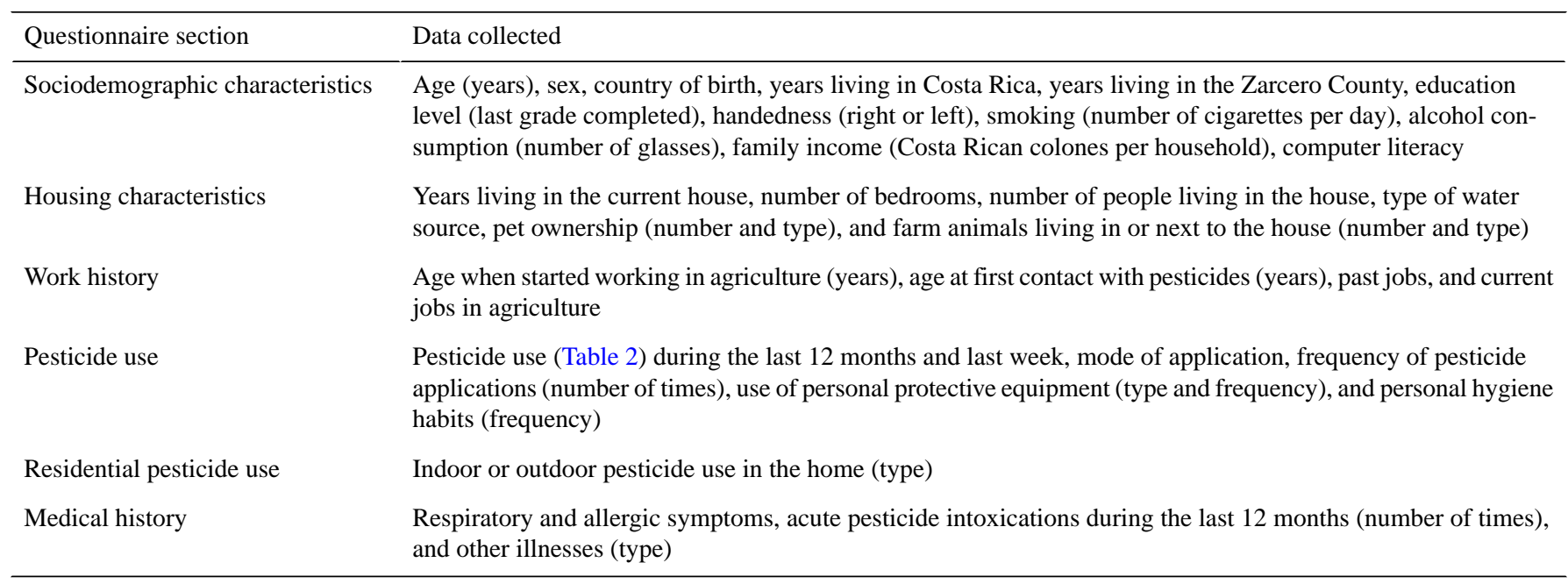

Table 2. Most frequently used pesticides (active ingredients; ordered from most frequently use to the least frequently used) in agricultural farms in the Zarcero County, Costa Rica ${ }^{\mathrm{a}}$.

\begin{tabular}{|c|c|c|c|}
\hline Active ingredient & Commercial names & Chemical subgroup & Group of action \\
\hline Chlorothalonil & Bravo, Bravonil, Knight, Talonil, Thalonex, Folio Gold, Odeon & Chloronitriles & Fungicide \\
\hline Benfuracarb & Oncol & Carbamates & Insecticide \\
\hline Mancozeb & Dithane, Mancol, Ridomil, Titan & Dithiocarbamates & Fungicide \\
\hline Boscalid & Bellis, Endura & Pyridinecarboxamids & Fungicide \\
\hline Acephate & Acefate, Orthene, Yucal & Organophosphates & Insecticide \\
\hline Phorate & Forato, Thimet, Thimetoato, Timefor & Organophosphates & Insecticide \\
\hline Fenamiphos & Fenemiphos, Nemacur & Organophosphates & Insecticide \\
\hline Chlorpyrifos & Agromil, Batazo, Baygon, Lorsban, Solver, Terminator, Swat & Organophosphates & Insecticide \\
\hline Carbofuran & Carbodan, Curator, Furadan & Carbamates & Insecticide \\
\hline Cypermethrin & Best, Cascabel, Cipermetrina, Combat, Cruz Verde, Tigre, Excalibur & Pyrethroids & Insecticide \\
\hline Propamocarb & Acrobat CT, Previcur, Proplant, Prevalor & Carbamates & Fungicide \\
\hline Paraquat & Gramoxone, Preglone, Rafaga & Bipyridiliums & Herbicide \\
\hline Propineb & Antracol, Inicol, Taifen & Dithiocarbamates & Fungicide \\
\hline
\end{tabular}

${ }^{a}$ Modified from: Ramírez et al, 2016 [32]. Pesticides are ordered from most frequently used to the least frequently used.

\section{Biological Sample Collection and Analyses}

\section{Urine Samples}

Spot urine samples were collected during the baseline and follow-up visits in plastic containers of $100 \mathrm{~mL}$ (Vacuette, sterile). Specimens were stored at $4^{\circ} \mathrm{C}$ until the end of the fieldwork day. Then, samples were aliquoted in $15-\mathrm{mL}$ plastic test tubes (PerformRTM Centrifuge tubes, Labcon, sterile) and stored at $-20^{\circ} \mathrm{C}$ until their shipment at $4^{\circ} \mathrm{C}$ to Lund University, Sweden, for analysis.

Urine samples will be analyzed for multiple pesticide metabolites including, but not limited to, ethylenethiourea (ETU, a metabolite of mancozeb); propylenethiourea (PTU, a metabolite of propineb); 3,5,6-trichloropyridinol (TCP, a metabolite of chlorpyrifos); 3-phenoxybenzoic acid (3-PBA, a metabolite of pyrethroids permethrin, cypermethrin, deltamethrin, and cyfluthrin); and hydroxy pyrimethanil (a metabolite of pyrimethanil). These pesticides and their metabolites were selected because they are among the most commonly used in Zarcero [32] and for which biomarkers of exposure are available. Briefly, urine specimens will be analyzed using tandem mass spectrometry and high-performance liquid chromatography $[37,38]$. The limit of detection (LOD) are as follows: ethylenethiourea, $0.08 \mathrm{ng} / \mathrm{mL}$; propylenethiourea, 0.1 $\mathrm{ng} / \mathrm{mL}$; TCP, $0.05 \mathrm{ng} / \mathrm{mL}$; 3-PBA, $0.03 \mathrm{ng} / \mathrm{mL}$; and hydroxy pyrimethanil, $0.1 \mathrm{ng} / \mathrm{mL}$. In all sample batches, chemical blanks and in-house quality control samples will be included to ensure the quality of all measurements; additionally, the analyses of TCP and 3-PBA are part of the round robin interlaboratory 
comparison program (University of Erlangen-Nuremberg, Germany) with results within the tolerance limits. Furthermore, urine samples will be analyzed for creatinine and specific gravity so that pesticide metabolite concentrations can be adjusted for differences in urinary dilution [39].

\section{Hair Samples}

Hair samples ( 20-30 strands) were collected from the occipital region, within $2 \mathrm{~mm}$ from the scalp, using stainless-steel scissors during the follow-up study visit. The samples were then stored at room temperature in sterile plastic bags until their shipment to the Federal University of Bahia, Brazil.

Hair specimens will be analyzed for manganese $(\mathrm{Mn})$, which is contained in ethylene bisdithiocarbamate fungicides, such as mancozeb. Briefly, the nearest centimeter scalp (proximal end) of hair will be sonicated for $20 \mathrm{~min}$ in $0.5 \%$ Triton, rinsed 5 times with ultrapure water, sonicated for $10 \mathrm{~min}$ in $1-\mathrm{N}$ nitric acid, rinsed once with $1-\mathrm{N}$ nitric acid, and then rinsed 5 times with ultrapure water [40]. Approximately $10 \mathrm{mg}$ of hair will be digested with $2 \mathrm{~mL}$ of concentrated $\mathrm{HNO}_{3}$ spectroscopic-grade acid in a microwave digestion oven (Mars-Express6, CEM, USA). The digested material will be diluted to $10 \mathrm{~mL}$ with ultrapure water. Hair samples, certified reference material (Human hair, International Atomic Energy Agency 086), and reagent blanks will be analyzed using electrothermal atomic absorption spectrometry with Zeeman background correction [41]. The analytical LOD for hair Mn concentrations will be set at $0.05 \mu \mathrm{g} / \mathrm{L}$.

\section{Toenail Samples}

Toenail samples were collected during the follow-up study visit. Participants were asked to cut their toenails with clean stainless-steel nail clippers and put them inside of a sterile plastic bag. Toenail specimens were stored at room temperature until their shipment to Federal University of Bahia, Brazil.

Toenail samples will be analyzed for Mn using the same procedure described above for hair samples. Briefly, nails will be washed in a Triton X-100 solution, put in acetone, repeatedly rinsed with ultrapure water, and then dried in an oven. Later, the dried nails will be digested with spectroscopic-grade acid in a microwave digestion oven (Mars-Express6, CEM), diluted to $10 \mathrm{~mL}$ with ultrapure water, and analyzed electrothermal atomic absorption spectrometry with Zeeman background correction $[42,43]$. All processed samples and reference material from the International Atomic Energy Agency (ie, 085) will be analyzed in duplicates. The analytical LOD for toenail $\mathrm{Mn}$ concentrations will be set at $0.05 \mu \mathrm{g} / \mathrm{L}$.

\section{Assessment of Health Outcomes}

\section{Symptoms of Acute Pesticide Poisoning}

Participants were administered a checklist of symptoms of acute organophosphate and carbamate poisoning (eg, excessive salivation, lacrimation, vomiting, and diarrhea) during the 12 -month period before the baseline study visit. This checklist has been previously used in studies of Latin American farm workers $[28,44]$.

\section{Respiratory and Allergic Outcomes}

A short version of the European Community Respiratory Health Study II questionnaire [45] was administered to study participants to identify respiratory symptoms (eg, wheezing, shortness of breath, coughing, and phlegm), respiratory diseases (eg, asthma and chronic bronchitis), allergic outcomes (eg, rhinitis and eczema), and common respiratory hazards such as smoking and pet ownership [46]. This questionnaire has been previously used in studies of Costa Rican populations [47-49].

\section{Neurobehavioral Outcomes}

Study participants were administered the following eight neurobehavioral tests: Animals and words with initial letter " $F$ " (to assess semantic and phonemic verbal fluency) [50]; Digit Span (working memory) [51]; Digit Symbol (visual perception abilities) [51]; Digit Vigilance (sustained attention and psychomotor speed) [52]; Trails Making Test Part A (executive function) [53]; Finger Tapping (psychomotor speed and coordination) [53]; Purdue Pegboard (fine motor function) [54]; and Brief Symptom Inventory (behavioral disorders including somatization, obsessive-compulsion, depression, anxiety, hostility, and psychoticism) [55].

These tests were selected on the basis of previous studies of Latin American populations exposed to pesticides [28,29], administration time, and cultural sensitivity [56]. Neurobehavioral assessments were conducted by two trained psychometricians and supervised by a physician with extensive experience on neurobehavioral testing. Quality assurance measures included pilot testing and review of recorded assessments.

\section{Brain Activity}

We used fNIRS (NIRSport, NIRx Medical Technologies, Los Angeles, CA, USA) to assess the cortical function associated with pesticide exposure in a random subsample of 50 study participants; a detailed description of our study methods can be found elsewhere [57]. Specifically, in this study, we hypothesized that higher pesticide exposures would be associated with more atypical brain activation patterns related to attention, working memory, and executive function. As these cognitive processes commonly elicit cortical activity within the bilateral dorsolateral prefrontal cortices [58-60], we targeted these regions with fNIRS. To engage our participants in tasks that required these cognitive abilities, each participant completed 3 computer-based tests that were optimized for neuroimaging applications. These tasks included the Wisconsin Card Sort test (an executive function and cognitive flexibility task) [60], Sternberg test (a letter-retrieval working memory task) [59], and Go/No-go test (an attention and impulse control task) [58]. Each task was conducted on a laptop computer that was dedicated to the fNIRS assessment and was completed on site.

\section{Cardiometabolic Outcomes: Blood Pressure and Anthropometric Measurements}

Trained research assistants measured systolic and diastolic blood pressure at two different time points (ie, at the beginning of "Station 1 " and "Station 3 " and about 1.5 hours apart from each other) during the baseline study visit using an automatic sphygmomanometer (Advantage 6021N). In addition, they 
measured participants' height $(\mathrm{cm})$ and weight $(\mathrm{kg})$ using a portable stadiometer and a digital scale (Tanita BC533, Arlington Heights, IL, USA). Waist circumference (cm) was measured using a tape measure Hoechstmass (Hoechstmass Balzer GmbH, Sulzbach, Germany).

\section{Erythrocytic Acetylcholinesterase Activity}

Capillary blood samples were collected at the baseline visit according to the manual of the Test-mate ChE Cholinesterase Test System (Model 400; EQM Research Inc, Cincinnati, OH, USA). Briefly, a small lancet (size 30) was used to collect a small sample of $10 \mu \mathrm{m}$ from the tip of the index finger of each study participant and placed into a capillary tube. Blood samples were analyzed on site for the erythrocytic AChE activity and hemoglobin levels using the same collection instrument [61].

\section{Statistical Analyses}

We will explore differences in self-reported pesticide exposures and health outcomes (ie, respiratory and allergic as well as neurobehavioral and cardiometabolic outcomes, brain activity, symptoms of acute pesticide poisoning, and erythrocytic AChE activity) in farm workers from conventional and organic farms. Cumulative lifetime pesticide exposure, exposure during the last 12 months, and during the last week will be estimated using exposure intensity scores derived from a semiquantitative exposure algorithm (based on self-reported data on pesticides, personal protective equipment use, and personal hygiene habits) [18]. Exposure intensity scores will be calculated for each chemical family (eg, organophosphates and carbamates) and active ingredient (eg, phorate and chlorpyrifos) and then validated against urinary pesticide metabolite concentrations and hair and toenail Mn concentrations using Spearman correlation coefficients and multivariate mixed-effects regression models [22]. We aim to use multiple imputation techniques to replace pesticide metabolite or Mn concentrations below the limit of detection [62]. In addition, we will fit mixed-effects models to examine the reproducibility of urinary pesticide concentrations by calculating ICCs (an ICC of $<0.50$ indicates poor reliability) [63]. If appropriate, we will then average urinary pesticide metabolite concentrations across the repeated samples collected for each study participant.

Associations of pesticide exposure with health outcomes of interest will be examined using both exposure scores and biomarkers of exposure. More specifically, we will fit linear or logistic (depending on the outcome) mixed-effects regression models (with the variable "participant" as random effect and other variables, such as outcome and covariates, as fixed effects) to explore the association of pesticide exposure with the following: (1) self-reported symptoms of acute pesticide poisoning in the last 12 months; (2) self-reported symptoms of respiratory and allergic symptoms and outcomes; (3) neurobehavioral outcomes and brain activity; (4) cardiometabolic effects (ie, obesity and hypertension); and (5) erythrocytic AChE activity. These mixed-effects models will allow us to take into account the correlation between and within farms as well as between and within farm workers. Furthermore, we will fit generalized additive models to examine the nonlinearity of the exposure-outcome associations.
We will identify potential confounders and known predictors of the health outcomes of interest (eg, age and education level for neurobehavioral outcomes) using directed acyclic graphs and will include them a priori in our regression models. Furthermore, we will assess other potential confounders by adding them, one at a time, to the final models (models with $a$ priori covariates). Additional covariates will be possibly included in the final models if they materially changed the magnitude of one or more exposure coefficients $(>10 \%)$. Missing values $(<10 \%)$ for covariates will be imputed by randomly selecting a value from the dataset or using multiple imputation techniques [62]. Statistical analyzes will be performed using STATA (Stata Corporation) and R ( R Foundation for Statistical Computing).

\section{Results}

The fieldwork for this study was conducted between May 2016 and August 2016. A total of 300 participants, including 113 farm owners and 187 workers from nine organic (48 participants) and 83 conventional (252 participants) horticultural smallholder farms from Zarcero County, Costa Rica, were enrolled. We had a $6.3 \%$ (281/300) loss to follow-up of study participants between the baseline and follow-up study visits (conducted 2-4 weeks apart). During the study implementation, we observed that farms were, on average, smaller than we expected (about three owners or workers per farm) and that there were not as many organic farms in the study area as anticipated (only 10 farms out of the 25 that we expected). Interviews to farm owners and key community actors conducted during this study revealed that many organic farm owners had recently started using synthetic pesticides due to the increasing costs of growing organic produce and getting certified as organic producers. Given the limited number of organic farms in the study area, we decided to include all farm owners and workers from organic farms located in the study area or within $5 \mathrm{~km}$ from it. In addition, to reach the targeted sample of 300 participants, we had to enroll more conventional farm owners and workers than what we had anticipated. Data analyses are ongoing and expected to be published between 2019 and 2021.

\section{Discussion}

This study has several limitations. First, its cross-sectional design will prevent us from identifying causal associations of pesticide exposure with health effects of interest. Second, we will not be able to exclude the possibility that there is recall or information bias, especially when relying on self-reported exposure to pesticides. In our study population, this bias may have worsened under the following conditions: (1) most study participants had a relatively low educational level; (2) pesticide use varied by crop and season; and (3) some farm owners did not communicate the specific pesticides that were used in their farms by their employees. Therefore, the validation of self-reported pesticide exposure data against biomarkers of exposure is crucial. Third, given that we had to enroll more conventional farm owners and workers than what we expected, and this could potentially threaten the internal validity of our study, we will assess participants' pesticide exposures using 
exposure intensity scores and biomarker concentrations in addition to their farming practices. We will also run analyses using only data from the conventional farms to evaluate the effects of the miscalculated sample size on our exposure-outcome associations. Fourth, we observed some significant differences between owners and workers from conventional and organic farms (eg, seasonal workers, differences in country of origin, and education level) that could potentially confound the exposure-outcome associations. Hence, it was important to also collect detailed information on confounding factors and predictors of the outcomes of interest.

The limitations of this study are offset by notable strengths, including (1) the quantification of pesticide metabolites and $\mathrm{Mn}$ concentrations in different biological matrices, which will allow us to validate the exposure information collected via questionnaires (or at least data from recent exposures given the relatively short half-lives of some of the biomarkers of exposure); (2) the comparison of workers and owners from conventional and organic farms using comprehensive questionnaires on occupational pesticide exposure; and (3) the assessment of health outcomes using internationally standardized tests that will allow for direct comparison of the results from this study to those from studies of other populations.

This study is one of the first studies to examine the health effects of exposure to a wide range of pesticides on Latin American workers from conventional and organic farms. In addition, this is one the first epidemiological studies to examine the association of pesticide exposure with brain cortical activity in farm workers. We expect that this study will provide critical data on how occupational exposure to common pesticides may affect farm owners' and workers' health. Finally, we hope that this study will allow us to identify strategies to reduce pesticide exposure in farm workers and will lay the groundwork for a future longitudinal study of health outcomes in farm owners and workers exposed to pesticides.

\section{Acknowledgments}

We gratefully acknowledge the study participants and staff (A Alfaro, C Hyland, A Campos, S Colombari, M Quirós-Lépiz, G Rodríguez, A Ulloa, and H Wey). We would also like to thank D Rojas for his support with the fNIRS assessments, C Wesseling and B van Wendel de Joode for their assistance with the questionnaire design, B Eskenazi for her insights on the neurobehavioral test selection, and Christian Schindler for his statistical support. This work was made possible by research supported by the Swiss Federal Institute of Aquatic Science and Technology (EAWAG), Universidad Nacional in Costa Rica, Forschungsfonds of the University of Basel, and the Swiss Network for International Studies (SNIS).

\section{Authors' Contributions}

MSW is the principal investigator of the PESTROP project, responsible for the overall study coordination. AMM is the project leader of the PESTROP project in Costa Rica and, together with SF, is responsible for the study design, fieldwork supervision, and data analyses. JMB and RGV designed and implemented the fNIRS protocol. PS, FTW, CS, RILE, and FRM contributed to the development of the study protocols and questionnaires. PS also contributed to the fieldwork supervision. CHL and JAMF contributed to the development of the study protocols and will be responsible for the analyses of the biological samples. SF, in close collaboration with AMM and MSW, drafted this manuscript.

\section{Conflicts of Interest}

None declared.

\section{Multimedia Appendix 1}

Peer-review reports.

[PDF File (Adobe PDF File), 199KB-Multimedia Appendix 1]

\section{References}

1. Zhang W, Jiang F, Ou J. Global pesticide consumption and pollution: with China as a focus. 2011 Aug Presented at: International Academy of Ecology and Environmental Sciences; 2011; Hong Kong p. 125-144.

2. van den Berg H, Zaim M, Yadav RS, Soares A, Ameneshewa B, Mnzava A, et al. Global trends in the use of insecticides to control vector-borne diseases. Environ Health Perspect 2012 Apr;120(4):577-582 [FREE Full text] [doi: 10.1289/ehp.1104340] [Medline: 22251458]

3. Food and Agriculture Organization of the United Nations. 2018. Statistics and Database of the Food and agriculture Organization of the United Nations (FAOSTAT) URL: http://www.fao.org/faostat/en/ [accessed 2018-08-31] [WebCite Cache ID 723qXCJRz]

4. Weiss F, Leuzinger M, Zurbrügg C, Eggen R. Chemical Pollution in Low- and Middle-Income Countries Chemical Pollution in Low- and Middle-Income Countries. In: Eawag. Dübendorf: Swiss Federal Institute of Aquatic Science and Technology; 2016.

5. The Lancet. Phasing out harmful use of pesticides. The Lancet 2017 Mar;389(10074):1076. [doi: 10.1016/S0140-6736(17)30766-3] 
6. Feola G, Binder CR. Why don't pesticide applicators protect themselves? Exploring the use of personal protective equipment among Colombian smallholders. Int J Occup Environ Health 2010;16(1):11-23. [doi: 10.1179/107735210800546218] [Medline: 20166315]

7. Negatu B, Kromhout H, Mekonnen Y, Vermeulen R. Occupational pesticide exposure and respiratory health: a large-scale cross-sectional study in three commercial farming systems in Ethiopia. Thorax 2017 Dec;72(6):498-499. [doi: 10.1136/thoraxjnl-2016-208924] [Medline: 27879416]

8. Schreinemachers P, Balasubramaniam S, Boopathi NM, Ha CV, Kenyon L, Praneetvatakul S, et al. Farmers' perceptions and management of plant viruses in vegetables and legumes in tropical and subtropical Asia. Crop Protection 2015 Sep;75:115-123. [doi: 10.1016/j.cropro.2015.05.012]

9. Macfarlane E, Carey R, Keegel T, El-Zaemay S, Fritschi L. Dermal exposure associated with occupational end use of pesticides and the role of protective measures. Saf Health Work 2013 Sep;4(3):136-141 [FREE Full text] [doi: 10.1016/j.shaw.2013.07.004] [Medline: 24106643]

10. Suratman S, Edwards JW, Babina K. Organophosphate pesticides exposure among farmworkers: pathways and risk of adverse health effects. Rev Environ Health 2015;30(1):65-79. [doi: 10.1515/reveh-2014-0072] [Medline: 25741936]

11. Deziel NC, Friesen MC, Hoppin JA, Hines CJ, Thomas K, Freeman LEB. A review of nonoccupational pathways for pesticide exposure in women living in agricultural areas. Environ Health Perspect 2015 Jun;123(6):515-524 [FREE Full text] [doi: 10.1289/ehp.1408273] [Medline: 25636067]

12. Thundiyil J, Stober J, Besbelli N, Pronczuk J. Acute pesticide poisoning: a proposed classification tool. Bull World Health Organ 2008 Mar;86(3):205-209 [FREE Full text] [Medline: 18368207]

13. Chakraborty S, Mukherjee S, Roychoudhury S, Siddique S, Lahiri T, Ray MR. Chronic exposures to cholinesterase-inhibiting pesticides adversely affect respiratory health of agricultural workers in India. J Occup Health 2009;51(6):488-497 [FREE Full text] [Medline: 19851039]

14. London L, Nell V, Thompson M, Myers J. Effects of long-term organophosphate exposures on neurological symptoms, vibration sense and tremor among South African farm workers. Scand J Work Environ Health 1998 Feb;24(1):18-29 [FREE Full text] [Medline: 9562397]

15. Tago D, Andersson H, Treich N. Pesticides and health: a review of evidence on health effects, valuation of risks, and benefit-cost analysis. Adv Health Econ Health Serv Res 2014;24:203-295. [Medline: 25244910]

16. Azandjeme C, Bouchard M, Fayomi B, Djrolo F, Houinato D, Delisle H. Growing burden of diabetes in sub-saharan Africa: contribution of pesticides ? Curr Diabetes Rev 2013 Nov;9(6):437-449. [Medline: 24160309]

17. Muñoz-Quezada MT, Lucero BA, Iglesias VP, Muñoz MP, Cornejo CA, Achu E, et al. Chronic exposure to organophosphate (OP) pesticides and neuropsychological functioning in farm workers: a review. Int J Occup Environ Health 2016 Dec;22(1):68-79 [FREE Full text] [doi: 10.1080/10773525.2015.1123848] [Medline: 27128815]

18. Negatu B, Vermeulen R, Mekonnen Y, Kromhout H. A Method for Semi-quantitative Assessment of Exposure to Pesticides of Applicators and Re-entry Workers: An Application in Three Farming Systems in Ethiopia. Ann Occup Hyg 2016 Jul;60(6):669-683. [doi: 10.1093/annhyg/mew022] [Medline: 27109466]

19. Carles C, Bouvier G, Lebailly P, Baldi I. Use of job-exposure matrices to estimate occupational exposure to pesticides: A review. J Expo Sci Environ Epidemiol 2017 Dec;27(2):125-140. [doi: 10.1038/jes.2016.25] [Medline: 27189257]

20. Ismail AA, Bonner MR, Hendy O, Abdel Rasoul G, Wang K, Olson JR, et al. Comparison of neurological health outcomes between two adolescent cohorts exposed to pesticides in Egypt. PLoS One 2017;12(2):e0172696 [FREE Full text] [doi: 10.1371/journal.pone.0172696] [Medline: 28231336]

21. Thomas KW, Dosemeci M, Coble JB, Hoppin JA, Sheldon LS, Chapa G, et al. Assessment of a pesticide exposure intensity algorithm in the agricultural health study. J Expo Sci Environ Epidemiol 2010 Sep;20(6):559-569 [FREE Full text] [doi: 10.1038/jes.2009.54] [Medline: 19888312]

22. Coble J, Thomas KW, Hines CJ, Hoppin JA, Dosemeci M, Curwin B, et al. An updated algorithm for estimation of pesticide exposure intensity in the agricultural health study. Int J Environ Res Public Health 2011 Dec;8(12):4608-4622 [FREE Full text] [doi: 10.3390/ijerph8124608] [Medline: 22408592]

23. de Araújo AJ, de Lima JS, Moreira J, Jacob Sdo C, Soares Mde O, Monteiro MC, et al. [Multiple exposure to pesticides and impacts on health: a cross-section study of 102 rural workers, Nova Friburgo, Rio de Janeiro State, Brazil]. Cien Saude Colet 2007;12(1):115-130 [FREE Full text] [Medline: 17680063 ]

24. Ramírez-Santana M, Zúñiga L, Corral S, Sandoval R, Scheepers PTJ, Van der Velden K, et al. Assessing biomarkers and neuropsychological outcomes in rural populations exposed to organophosphate pesticides in Chile--study design and protocol. BMC Public Health 2015 Feb 10;15:116 [FREE Full text] [doi: 10.1186/s12889-015-1463-5] [Medline: 25881174]

25. Mohanty MK, Behera BK, Jena SK, Srikanth S, Mogane C, Samal S, et al. Knowledge attitude and practice of pesticide use among agricultural workers in Puducherry, South India. J Forensic Leg Med 2013 Nov;20(8):1028-1031. [doi: 10.1016/j.jflm.2013.09.030] [Medline: 24237813]

26. Wesseling C, van Wendel de Joode B, Keifer M, London L, Mergler D, Stallones L. Symptoms of psychological distress and suicidal ideation among banana workers with a history of poisoning by organophosphate or n-methyl carbamate pesticides. Occup Environ Med 2010 Nov;67(11):778-784 [FREE Full text] [doi: 10.1136/oem.2009.047266] [Medline: 20798019] 
27. Wesseling C, Keifer M, Ahlbom A, McConnell R, Moon J, Rosenstock L, et al. Long-term neurobehavioral effects of mild poisonings with organophosphate and n-methyl carbamate pesticides among banana workers. Int J Occup Environ Health 2002;8(1):27-34. [doi: 10.1179/oeh.2002.8.1.27] [Medline: 11843437]

28. Wesseling C, Aragón A, Rojas M, Blanco L, López L, Soto A, et al. Efectos del clorpirifos en la salud de trabajadores bananeros de La Lima, Honduras. Heredia: SALTRA, IRET-UNA, CISTA, UNAN-León; 2006:1-56.

29. van Wendel de Joode B, Wesseling C, Kromhout H, Monge P, García M, Mergler D. Chronic nervous-system effects of long-term occupational exposure to DDT. Lancet 2001 Mar 31;357(9261):1014-1016. [doi: 10.1016/S0140-6736(00)04249-5] [Medline: 11293598 ]

30. Shennan C, Krupnik TJ, Baird G, Cohen H, Forbush K, Lovell RJ, et al. Organic and Conventional Agriculture: A Useful Framing? Annu Rev Environ Resour 2017 Oct 17;42(1):317-346. [doi: 10.1146/annurev-environ-110615-085750]

31. Costa C, García-Lestón J, Costa S, Coelho P, Silva S, Pingarilho M, et al. Is organic farming safer to farmers' health? A comparison between organic and traditional farming. Toxicol Lett 2014 Oct 15;230(2):166-176 [FREE Full text] [doi: 10.1016/j.toxlet.2014.02.011] [Medline: 24576785]

32. Ramírez F, Chaverri F, Fournier M, de la Cruz E, Bravo V, Echeverría S, et al. Las buenas prácticas agrícolas en el uso y manejo de agroquímicos en la zona hortícola de Zarcero, Alajuela. Informe de Avance de Primer Año. Heredia, Costa Rica: Instituto Regional de Estudios en Sustancias Tóxicas; 2016.

33. INEC Costa Rica. 2015. Proyecto VI Censo Nacional Agropecuario 2014 URL: http://www.inec.go.cr/sites/default/files/ documentos/agropecuario/metodologias/documentos metodologicos/meagropeccenagro2014-001.pdf] $[$ WebCite Cache ID $723 \mathrm{rClMha}]$

34. Schaub N. Risk of pesticide input into a tropical stream due to spatial proximity and erosion - Case study in the Tapezco catchment (Costa Rica). Institute of Environmental Engineering, ETH Zürich 2016 MSc Thesis.

35. Open Data Kit. 2018. The standard for mobile data collection URL: https://opendatakit.org/ [accessed 2018-08-30] [WebCite Cache ID 723raIBjZ]

36. Neupane D, Jørs E, Brandt L. Pesticide use, erythrocyte acetylcholinesterase level and self-reported acute intoxication symptoms among vegetable farmers in Nepal: a cross-sectional study. Environ Health 2014 Nov 20;13:98 [FREE Full text] [doi: 10.1186/1476-069X-13-98] [Medline: 25409889]

37. Ekman E, Maxe M, Littorin M, Jönsson BAG, Lindh CH. High-throughput method for the analysis of ethylenethiourea with direct injection of hydrolysed urine using online on-column extraction liquid chromatography and triple quadrupole mass spectrometry. J Chromatogr B Analyt Technol Biomed Life Sci 2013 Sep 01;934:53-59 [FREE Full text] [doi: 10.1016/j.jchromb.2013.06.035] [Medline: 23896430]

38. Ekman E, Faniband MH, Littorin M, Maxe M, Jönsson BAG, Lindh CH. Determination of 5-hydroxythiabendazole in human urine as a biomarker of exposure to thiabendazole using LC/MS/MS. J Chromatogr B Analyt Technol Biomed Life Sci 2014 Dec 15;973C:61-67 [FREE Full text] [doi: 10.1016/j.jchromb.2014.10.003] [Medline: 25464096]

39. Barr DB, Wilder LC, Caudill SP, Gonzalez AJ, Needham LL, Pirkle JL. Urinary creatinine concentrations in the U.S. population: implications for urinary biologic monitoring measurements. Environ Health Perspect 2005 Feb;113(2):192-200 [FREE Full text] [doi: 10.1289/ehp.7337] [Medline: 15687057]

40. Eastman RR, Jursa TP, Benedetti C, Lucchini RG, Smith DR. Hair as a biomarker of environmental manganese exposure. Environ Sci Technol 2013 Feb 05;47(3):1629-1637 [FREE Full text] [doi: 10.1021/es3035297] [Medline: 23259818]

41. Menezes-Filho JA, Paes CR, Pontes AMDC, Moreira JC, Sarcinelli PN, Mergler D. High levels of hair manganese in children living in the vicinity of a ferro-manganese alloy production plant. Neurotoxicology 2009 Nov;30(6):1207-1213 [FREE Full text] [doi: 10.1016/j.neuro.2009.04.005] [Medline: 19393689]

42. Ayodele JT, Bayero AS. Manganese concentrations in hair and fingernail of some Kano inhabitants. J Appl Sci Environ Manag 2010;14(1). [doi: 10.4314/jasem.v14i1.56472]

43. Mehra R, Juneja M. Fingernails as biological indices of metal exposure. J Biosci 2005 Mar;30(2):253-257. [doi: 10.1007/BF02703706]

44. Rodezno RA, Lundberg I, Escalona E. Development of a questionnaire in spanish on neurotoxic symptoms. Am J Ind Med 1995 Oct;28(4):505-520. [doi: 10.1002/ajim.4700280407]

45. ECRHS. 2018. European Community Respiratory Health Survey URL: http://www.ecrhs.org/Quests.htm [accessed 2018-08-30] [WebCite Cache ID 723pw1cX4]

46. Burney PG, Luczynska C, Chinn S, Jarvis D. The European Community Respiratory Health Survey. Eur Respir J 1994 May;7(5):954-960 [FREE Full text] [Medline: $\underline{\text { 8050554] }}$

47. Fieten KB, Kromhout H, Heederik D, van Wendel de Joode B. Pesticide exposure and respiratory health of indigenous women in Costa Rica. Am J Epidemiol 2009 Jun 15;169(12):1500-1506. [doi: 10.1093/aje/kwp060] [Medline: 19372212]

48. Rodríguez-Zamora MG, Medina-Escobar L, Mora G, Zock J, van Wendel de Joode B, Mora AM. Dust exposure in workers from grain storage facilities in Costa Rica. Int J Hyg Environ Health 2017 Dec;220(6):1039-1045. [doi:

10.1016/j.ijheh.2017.06.002] [Medline: 28663028]

49. Rodríguez-Zamora MG, Zock J, van Wendel de Joode B, Mora AM. Respiratory Health Outcomes, Rhinitis, and Eczema in Workers from Grain Storage Facilities in Costa Rica. Ann Work Expo Health 2018 Nov 12;62(9):1077-1086. [doi: 10.1093/annweh/wxy068] [Medline: 30016387] 
50. Ostroski-Solís P, Ardila A, Rosselli M. Neuropsi Evaluación Neuropsicológica. Mexico city: Universitad Nacional Autónoma de México; 1998.

51. Wechsler D. Manual for the Wechsler Adult Intelligence Scale. New York: Psychological Corporation; 1981.

52. Lewis R, Rennick P. Manual for the Repeatable Cognitive-Perceptual-Motor Battery. Grosse Point: Axon; 1979.

53. Reitan R. Neuropsychological Test Battery: Theory and Clinical Interpretation. Tucson: Neuropsychological Press; 1985.

54. Costa LD, Vaughan HGJ, Levita E, Farber N. Purdue Pegboard as a predictor of the presence and laterality of cerebral lesions. Journal of Consulting Psychology 1963;27(2):133-137. [doi: 10.1037/h0040737]

55. Derogatis L, Spencer P. The Brief Symptom Inventory: Administration, ScoringProcedures Manual I. Baltimore: John Hopkins University School of Medicine; 1982.

56. WHO. Neurobehavioral Core Test Battery: Operational Guide. Geneva: World Health Organization; 1986.

57. Baker JM, Rojas-Valverde D, Gutiérrez R, Winkler M, Fuhrimann S, Eskenazi B, et al. Portable Functional Neuroimaging as an Environmental Epidemiology Tool: A How-To Guide for the Use of fNIRS in Field Studies. Environ Health Perspect 2017 Dec 21;125(9):094502 [FREE Full text] [doi: 10.1289/EHP2049] [Medline: 28937962]

58. Cui X, Bray S, Bryant DM, Glover GH, Reiss AL. A quantitative comparison of NIRS and fMRI across multiple cognitive tasks. Neuroimage 2011 Feb 14;54(4):2808-2821 [FREE Full text] [doi: 10.1016/j.neuroimage.2010.10.069] [Medline: 21047559]

59. Ehlis A, Bähne CG, Jacob CP, Herrmann MJ, Fallgatter AJ. Reduced lateral prefrontal activation in adult patients with attention-deficit/hyperactivity disorder (ADHD) during a working memory task: a functional near-infrared spectroscopy (fNIRS) study. J Psychiatr Res 2008 Oct;42(13):1060-1067. [doi: 10.1016/j.jpsychires.2007.11.011] [Medline: 18226818]

60. Monchi O, Petrides M, Petre V, Worsley K, Dagher A. Wisconsin Card Sorting revisited: distinct neural circuits participating in different stages of the task identified by event-related functional magnetic resonance imaging. J Neurosci 2001 Oct 01;21(19):7733-7741 [FREE Full text] [Medline: 11567063]

61. EQM Research, Inc. 2003. Test-mate ChE Cholinesterase Test System (Model 400) URL: http://www.eqmresearch.com/ Manual-E.pdf [accessed 2018-11-14] [WebCite Cache ID 73urQFt0E]

62. Lubin JH, Colt JS, Camann D, Davis S, Cerhan JR, Severson RK, et al. Epidemiologic evaluation of measurement data in the presence of detection limits. Environ Health Perspect 2004 Dec 13;112(17):1691-1696 [FREE Full text] [doi: 10.1289/ehp.7199] [Medline: 15579415]

63. Koo TK, Li MY. A Guideline of Selecting and Reporting Intraclass Correlation Coefficients for Reliability Research. $\mathbf{J}$ Chiropr Med 2016 Jun;15(2):155-163 [FREE Full text] [doi: 10.1016/j.jcm.2016.02.012] [Medline: 27330520]

\author{
Abbreviations \\ 3-PBA: 3-phenoxybenzoic acid \\ AChE: acetylcholinesterase \\ fNIRS: functional near-infrared spectroscopy \\ GPS: global positioning system \\ ICC: intraclass correlation coefficient \\ LOD: limit of detection \\ LMICs: low- and middle-income countries \\ Mn: manganese \\ TCP: 3,5,6-trichloropyridinol
}

Edited by G Eysenbach, N Kuter; submitted 30.04.18; peer-reviewed by S Cortés Arancibia, R Kanter, FA Shafie; comments to author
03.08.18; revised version received 30.08.18; accepted 10.10.18; published 25.01.19
Please cite as:
Fuhrimann S, Winkler MS, Staudacher P, Weiss FT, Stamm C, Eggen RIL, Lindh CH, Menezes-Filho JA, Baker JM, Ramírez-Muñoz
F, Gutiérrez-Vargas R, Mora AM
Exposure to Pesticides and Health Effects on Farm Owners and Workers From Conventional and Organic Agricultural Farms in
Costa Rica: Protocol for a Cross-Sectional Study
JMIR Res Protoc $2019 ; 8(1):$ : 10914
URL: http://www.researchprotocols.org/2019/1/e10914/
doi: $10.2196 / 10914$
PMID: $\underline{30681969}$

(C) Samuel Fuhrimann, Mirko S Winkler, Philipp Staudacher, Frederik T Weiss, Christian Stamm, Rik IL Eggen, Christian H Lindh, José A Menezes-Filho, Joseph M Baker, Fernando Ramírez-Muñoz, Randall Gutiérrez-Vargas, Ana M Mora. Originally 
published in JMIR Research Protocols (http://www.researchprotocols.org), 25.01.2019. This is an open-access article distributed under the terms of the Creative Commons Attribution License (https://creativecommons.org/licenses/by/4.0/), which permits unrestricted use, distribution, and reproduction in any medium, provided the original work, first published in JMIR Research Protocols, is properly cited. The complete bibliographic information, a link to the original publication on http://www.researchprotocols.org, as well as this copyright and license information must be included. 